\title{
Pengenalan Penggunaan Biofilter sebagai Upaya Mengatasi Pencemaran Bahan Organik di Perairan Tambak di Kelurahan Lakkang, Kota Makassar
}

\section{Introducing Biofilter as a Technique for Solving a Problem of Organic Pollutan at Brachiswater Pond at Lakkang Village, Makassar}

\author{
${ }^{1}$ Nita Rukminasari, ${ }^{1}$ Nadiarti Nurdin, ${ }^{1}$ Khusnul Yaqin, ${ }^{1}$ Moh. Tauhid Umar, \\ ${ }^{1}$ Irmawati, ${ }^{1}$ Dewi Yanuarita
}

${ }^{1}$ Program Studi Manajemen Sumberdaya Perairan, Fakultas Ilmu Kelautan dan Perikanan, Universitas Hasanuddin

Korespondensi: N. Rukminasari, nita.r@unhas.ac.id.

Naskah Diterima: 18 Juni 2019. Disetujui: 21 Januari 2020. Disetujui Publikasi: 17 Februari 2020

\begin{abstract}
Fish/shrimp culture at pond is one of income source for coastal community. Water sources for brackhiswater pond come from river and estuary. The quality of water source for this pond depend on the quality of river and estuary. On the other side, people use river to through it their waste not only domestic waste but also industrial waste along the river, consequently the pollutant in the river is high. Brackishwater pond along Tallo river has a source of water from River and Tallo Estuary. A high organic concentration in the Tallo River has a significantly effect to the production of shrimp/fish pond. A low water quality due to high organic matter could decrease the production of pond and farmers could not be able to grow out fish/shrimp for all year due to in particular month was occurred an increasing significantly of organic pollutant in the river. Introducing biofilter method to farmers for increasing pond water quality and reducing organic waste in the pond is very important, so farmer could apply this simple biofilter technique for solving a problem of a high organic matter in their pond. Applying biofilter techinique could be expected increasing water quality in the pond, consequently it could increase shrimp/pond production of farmers.
\end{abstract}

Keywords: Biofilter, organic pollutant, Shrimp/fish pond, Tallo River and Lakkang Village.

\begin{abstract}
Abstrak: Budidaya ikan/udang di tambak merupakan salah satu sumber pendapatan masyarakat pesisir. Sumber air di tambak biasanya berasal dari sungai dan muara sungai. Kualitas sumber air di tambak sangat tergantung kepada kualitas air sungai dan muara. Di sisi lain, sungai merupakan tempat pembuangan limbah baik limbah domestic maupun limbah industry yang ada di sepanjang sungai sehingga kandungan limbah baik limbah organik maupun non organik cenderung sangat tinggi di perairan sungai. Pertambakan di sepanjang muara sungai Tallo, Kelurahan Lakkang sumber airnya berasal dari Sungai dan Muara Sungai Tallo. Tingginya kandungan bahan organik di perairan Sungai Tallo sangat mempengaruhi produksi tambak masyarakat. Kondisi kualitas perairan yang rendah karena tingginya kandungan bahan organik menyebabkan semakin turunnya produksi tambak dan masyarakat tidak dapat membudidayakan ikan dan udangnya sepanjang tahun karena pada waktu-waktu tertentu terjadi peningkatan limbah bahan organik yang signifikan. Pengenalan metode biofilter untuk meningkatkan kualitas perairan tambak dan mengurangi limbah organik di tambak sangat penting untuk dilakukan sehingga masyarakat dapat memanfaatkan teknologi sederhana biofilter untuk mengatasi masalah tingginya konsentrasi bahan organik di tambak.
\end{abstract}


Dengan penerapan teknologi biofilter ini diharapkan terjadi peningkatan kualitas air tambak yang akan meningkatkan produksi budidaya udang/ikan.

Kata kunci: Biofilter, pencemaran, bahan organik dan Kelurahan Lakkang.

\section{Pendahuluan}

Kelurahan Lakkang, Kecamatan Tallo adalah kelurahan yang terletak di muara Sungai Tallo dan Pampang, dihuni oleh 261 KK dengan jumlah penduduk 947 jiwa yang terdiri dari 479 laki-laki dan 468 Perempuan. Kelurahan Lakkang memiliki potensi perikanan berupa pertambakan. Potensi perikanan ini cukup tinggi dan menjadi sumber pendapatan bagi sebagian masyarakat Lakkang. Luas wilayah mencapai 1,95 ha dengan luas area 1,65 km2. Wilayah Kelurahan Lakkang terletak di daerah aliran Sungai Tallo. Secara administratif terletak di Kecamatan Tallo Kota Makassar yang mana posisi geografis kelurahan terletak di E 05006’38,2 dan 119025,37,2 (Anonim, 2018).

Kelurahan Lakkang yang letaknya berdampingan dengan sungai Tallo menjadikan mata pencaharian utama masyarakatnya adalah dominan petambak. Kegiatan usaha budidaya udang windu dan bandeng menjadi profesi yang sudah dilakukan secara turun temurun di Kelurahan Lakkang. Masyarakat Lakkang bias dikatakan masih serumpun, kekeluargaan di Lakkang yang masih kuat tentu saja memberi dampak positif dan perlu dilestarikan. Namun adakalanya kurang mengembangkan perkonomian penduduk. Sebagai contoh, masyarakat tidak terbiasa menjual hasil panen bandengnya, mereka lebih suka membagikan hasil tangkapan ini pada tetangga maupun kerabatnya.

Keberhasilan budidaya ikan/udang di tambak salah satunya ditentukan oleh kualitas sumber air sungai atau muara. Petambak tradisional yang tidak memiliki fasilitas pengelolaan kualitas air yang masuk ke pertambakan, sangat tergantung kepada kualitas air yang masuk ke pertambakan dari sungai dan atau dari muara sungai. Di lain sisi, sungai dan muara sungai dijadikan tempat pembuangan limbah domestic maupun limbah industry sehingga kualitas air yang masuk ke pertambakan cenderung memiliki kualitas yang rendah dan banyak mengandung limbah bahan organik dan limbah inorganik lainnya, khususnya limbah bahan organik. Tingginya konsentrasi bahan organik di perairan menyebabkan rendahnya kualitas air dan rendahnya konsentrasi oksigen di malam hari, hal ini menyebabkan terganggunya metabolism ikan/udang yang dibudidayakan. Rendahnya kualitas sumber air di pertambakan Kelurahan Lakkang menyebabkan rendahnya hasil panen ikan/udang yang dibudidayakan.

Pengetahuan masyarakat tentang pengelolaan kualitas air tambak sangat rendah, masyarakat cenderung membiarkan kondisi buruknya kualitas air di pertambakan mereka. Oleh karena itu, rendahnya tingkat keberhasilan budidaya udang/tambak di Kelurahan Lakkang. Salah satu teknik untuk meningkatkan kualitas air di tambak atau di kolam adalah dengan menggunakan teknik biofilter. Biofilter adalah komponen dari sistem sirkulasi air tertutup hingga timbul pergantian senyawa terlarut yg terjadi akibat kegiatan mikroba (Anonim, 2008). Biofilter merupakan alat penyaring atau penjernih air dari bahan-bahan organik seperti kelor, eceng gondok kulit pisang dan bahan lain yang memiliki fungsi sebagai penyerap polutan air. biofilter sangat efektif digunakan dalam mengolah limbah. Proses filterisasi menghasilkan air bersih, terbebas dari bau, bahan organik dan bahan anorganik yang terdapat didalamnya.

Proses pengolahan air limbah dengan sistem biofilm atau biofilter dapat dilakukan secara aerobik, anerobik, atau gabungan proses anaerob-aerob. Proses aerobik dilakukan dengan kondisi adanya oksigen terlarut di dalam reaktor air limbah, dan proses anaerobik dilakukan dengan tanpa adanya oksigen dalam reaktor air limbah. Sedangkan proses kombinasi anaerob-aerob adalah merupakan gabungan proses anaerobik dan proses aerobik. Proses ini biasanya digunakan 
untuk menghilangan kandungan nitrogen di dalam air limbah. Pada kondisi aerobik terjadi proses nitrifikasi yakni nitrogen ammonium diubah menjadi nitrat (NH4+ $\rightarrow$ NO3 ) dan pada kondisi anaerobik terjadi proses denitrifikasi yakni nitrat yang terbentuk diubah menjadi gas nitrogen (Hikami, 1992). Menurut Lim dan Grady (1980), mekanisme yang terjadi pada reaktor biologis biakan melekat diam terendam adalah sebagai berikut: a) Transportasi dan adsorpsi zat organik dan nutrien dari fasa liquid ke fasa biofilm, b) Transportasi mikroorganisme dari fasa liquidke fasa biofilm, c) Adsorpsi mikroorganisme yang terjadi dalamlapisan biofilm, d) Reaksi metabolisme mikroorganisme yangterjadi dalam lapisan biofim, memungkinkan terjadinya mekanisme pertumbuhan, pemeliharaan, kematian dan lysis sel, e)Penempelan (attachment) dari sel, yaitu pada saat lapisan biofilm mulai terbentuk dan terakumulasi secara kontinyu dan bertahap (gradual) pada lapisan biofim, and f) Mekanisme pelepasan (detachment biofilm) dan produk lainnya (by product).

Sumber air tambak di pertambakan Kelurahan Lakkang berasal dari air Sungai Tallo, dimana kualitas air tambak sangat tergantung pada kualitas air Sungai Tallo. Adapun kondisi Sungai Tallo sangat dipengaruhi oleh aktivitas manusia dan masyarakat menjadikan Sungai Tallo sebagai tempat pembuangan limbah, sehingga kualitas air Sungai Tallo rendah. Masalah utama air Sungai Tallo adalah tinggi kadar bahan organik, sehingga kondisi ini mempengaruhi kondisi kualitas air tambak di Kel. Lakkang dan secara langsung akan mempengaruhi produksi ikan/udang petambak. Salah satu metode untuk mengatasi masalah tingginya bahan organik dalam air adalah melalui teknik biofilter.

Pengenalan teknik biofilter kepada petambak di Kelurahan Lakkang sangat penting dilakukan, karena dengan teknik biofilter ini akan meningkatkan kualitas air yang masuk ke tambak-tambak dengan menurunkan konsentrasi limbah/bahan organik yang masuk dari sungai/muara. Meningkatnya kualitas air yang baik ke pertambakkan akan meningkatkan keberhasilan budidaya udang/ikan, sehingga diharapkan teknik ini akan meningkatkan hasil budidaya para petambak dan akhirnya akan meningkatkan pendapatan petambak. Adapun tujuan kegiatan pengabdian ini adalah untuk memerkenalkan penggunaan dan manfaat teknik biofilter kepada petambak untuk mengurangi kadar bahan organik dan meningkatkan kualitas air tambak. Adapun manfaat dari kegiatan ini diharapkan petambak dapat mengaplikasikan teknik biofilter di tambaknya sehingga dapat meningkatkan produksi ikan/udangnya.

\section{Metode Pelaksanaan}

Tempat dan Waktu. Kegiatan pengabdian pada masyarakat ini dilaksanakan di Kelurahan Lakkang, Kecamatan Tallo, Kota Makassar pada bulan Juli - September 2018 (Gambar 1).

Khalayak Sasaran. Adapun khalayak sasaran kegiatan ini adalah petambak ikan dan udang di Kelurahan Lakkang, Kecamatan Tallo, Kota Makassar. Berdasarkan survey awal di kantor Kelurahan Lakkang, terdapat kurang lebih 30 petambak. Untuk kegiatan ini kami mengundang semua petambak untuk dapat berpartisipasi pada kegiatan ini.

Metode Pengabdian. Bentuk kegiatan pengabdian pada masyarakat meliputi penyuluhan tentang manfaat dan cara pembuatan biofilter. Kegiatan penyuluhan ini untuk memperkenal teknik biofilter untuk mengatasi masalah tingginya bahan organik dan meningkatkan kualitas air tambak. Pembuatan buku saku "Petunjuk pembuatan biofilter" dan pembagian buku saku kepada semua petambak. Kegiatan pembuatan buku saku ini bertujuan untuk memberikan paduan/pegangan petambak cara membuat biofilter, sehingga petambak dapat membuat biofilter secara mandiri. Kegiatan pengabdian kepada masyarakat ini dilaksanakan 


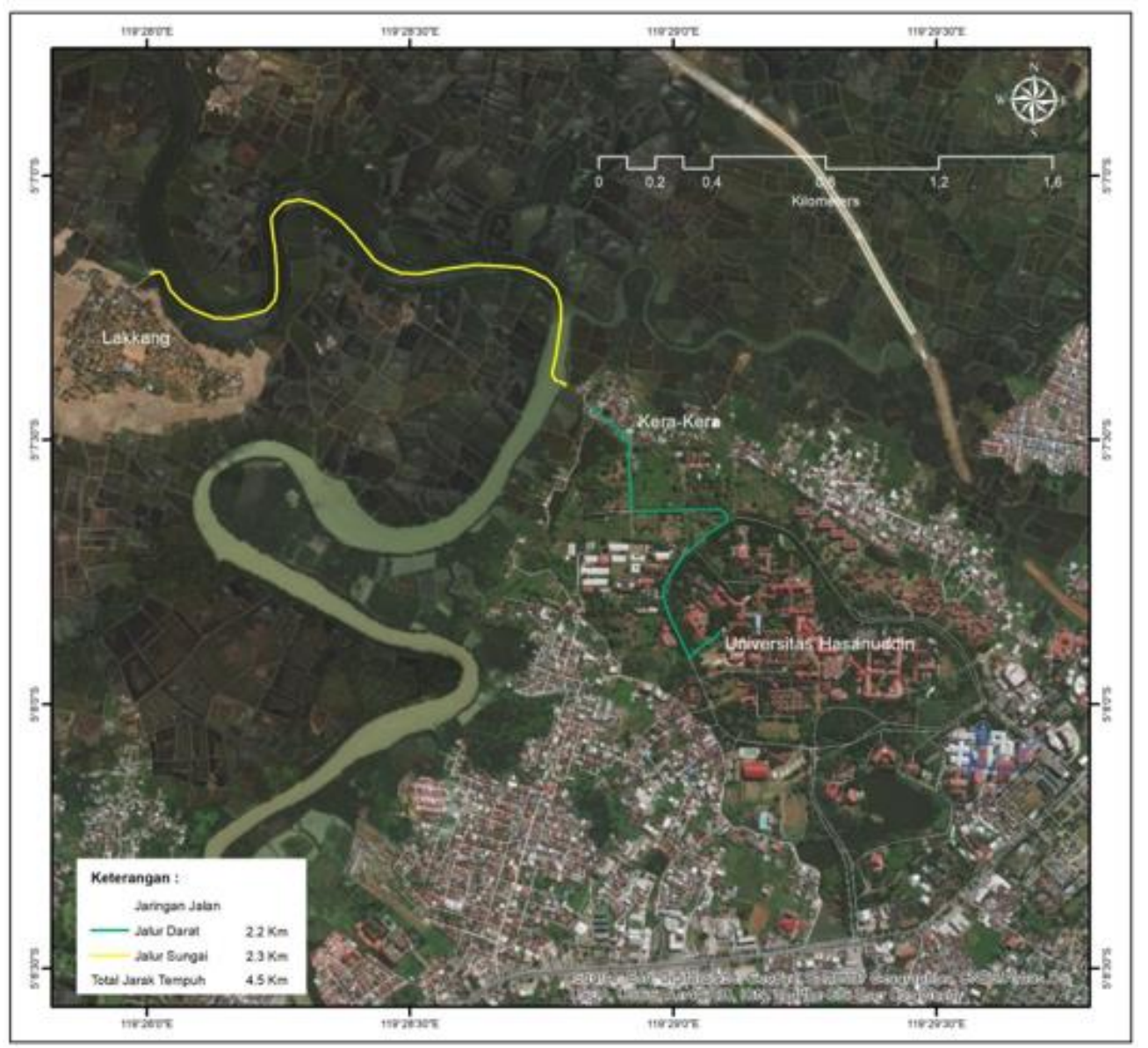

Gambar 1. Peta lokasi pengabdian, Kelurahan Lakkang, Kecamatan Tallo, Kota Makassar

menggunakan metode penyuluhan aktif-demonstratif meliputi: penjelasan teori kepada petambak mengenai manfaat dan cara pembuatan biofilter, pembentukan kelompok petambak untuk pembuatan biofilter dibeberapa areal tambak di Kelurahan Lakkang, pembagian buku saku Petunjuk Pembuatan Biofilter kepada petambak, dengan pembagian buku saku ini petambak mempunyai pegangan cara pembuatan biofilter sehingga dia mampu membuat biofilter secara mandiri. Tim pengabdi memberikan bimbingan kepada kelompok masyarakat pada khalayak sasaran yang telah ditunjuk dalam pembuatan unit biofilter yang akan dilakukan secara mandiri oleh petambak.

Indikator Keberhasilan. Indikator kegiatan pengabdian ini adalah tingkat partisipasi masyarakat dan penambahan pengetahuan petambak tentang biofilter, ketersediaan buku saku panduan pembuatan biofilter manuscript.

Metode Evaluasi. Selama kegiatan berlangsung, dilakukan evaluasi terhadap seluruh rangkaian kegiatan pengabdian, penyuluhan (penjelasan teori) sampai pelaksanaan demonstrasi (Rifa'i, dkk., 2017, 2018; Kudsiah, dkk., 2018; Rukminasari, dkk., 2016; Yaqin, dkk., 2017) dan pengerjaan pembuatan unit biofilter secara mandiri oleh khalayak sasaran.

\section{A. Kegiatan Penyuluhan}

\section{Hasil Kegiatan}

Kegiatan pengabdian pada masyarakat tentang "Pengenalan penggunaan biofilter sebagai upaya mengatasi pencemaran bahan organik di perairan tambak di Kelurahan Lakkang, Kota Makassar" diawali dengan kegiatan penyuluhan tentang "Manajemen tambak udang dengan biofilter kascing". Kegiatan penyuluhan ini 
diikuti oleh 24 peserta dari Kelurahan Lakkang dan dihadiri juga oleh Bapak Lurah dan beberapa staf kelurahan. Kegiatan penyuluhan ini dilaksanakan pada hari Jumat, 9 September 2018 di ruangan pertemuan Kelurahan Losari, Kota Makassar. Adapun pemateri dari kegiatan penyuluhan ini adalah salah satu staf Dosen Prodi MSP, FIKP, Unhas (Dr. Ir. Khusnul Yaqin, M.Sc.).

Pada saat kegiatan penyuluhan berlangsung, terlihat minat dan keingintahuan masyarakat cukup besar terhadap materi yang dijelaskan oleh pemateri hal ini terlihat dengan cukup banyaknya pertanyaan yang diajukan kepada pemateri serta aktifnya peserta dalam berdiskusi tentang materi yang dijelaskan. Penjelasan materi mengenai pentingnya memelihara dan menjaga kebersihan lingkungan berlangsung selama 1 jam. Dokumentasi kegiatan disajikan pada Gambar 2.
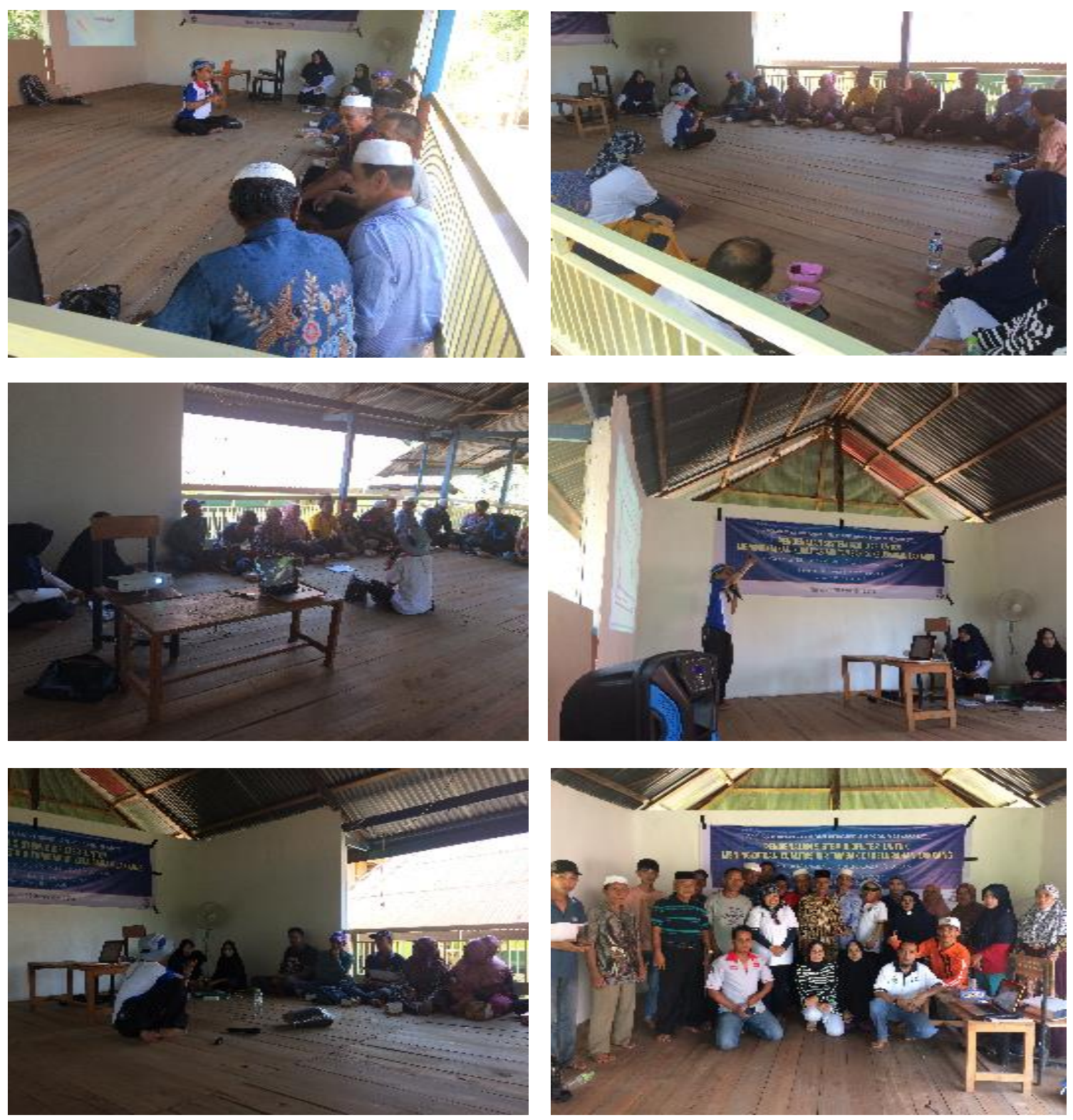

Gambar 2. Dolumentasi kegiatan penyuluhan di lokasi pengabdian

\section{B. Pembuatan Buku Saku Panduan Pembuatan Biofilter}

Setelah dilakukan penyuluhan tentang fungsi dan manfaat biofilter untuk meningkatkan kualitas air tambak, tim pengabdi membuat buku suku panduan pembuatan biofilter. Pembuatan buku saku ini bertujuan untuk panduan tertulis bagi petambak yang berminat menerapkan teknik biofilter di tambaknya. Adapun 
isi dari buku saku ini terdiri dari pengenal teori tentang biofilter, manfaat biofilter, bagian-bagian biofilter, bahan dan alat yang dibutuhkan untuk pembuatan biofilter, dan langkah-langkah pembuatan biofilter. Buku saku ini dibagikan kepada petambak, diharapkan dengan pembagian buku saku ini petambak dapat dengan mudah mempraktekkan pembuatan biofilter ditambaknya.

\section{Evaluasi Kegiatan}

Jangka waktu pelaksanaan kegiatan pengabdian pada masyarakat ini relative singkat, sehingga evaluasi hasil kegiatan hanya dapat dilakukan melalui observasi langsung pada saat kegiatan dilaksanakan. Observasi yang dilakukan meliputi tingkat partisipasi/kehadiran masyarakat pada saat kegiatan penyuluhan yang dilakukan.

Tingkat partisipasi/kehadiran masyarakat mengikuti kegiatan penyuluhan cukup tinggi, yaitu 24 peserta dan jumlah peserta yang berpartisipasi dalam kegiatan ini ditargetkan 25 orang, jadi secara keseluruhan kegiatan ini memenuhi target dari segi jumlah peserta. Rencana awal akan dibuatkan demplot biofilter di salah satu tambak di lokasi pengabdian, tapi berhubungan dana yang tersedia tidak mencukupi, akhirnya dibuat buku saku panduan pembuatan biofilter. Dengan pembuatan buku saku ini diharapkan petambak dapat membuat secara mandiri biofilter di tambaknya. Buku saku panduan pembuatan biofilter ini telah dibagikan kepada 20 orang petambak di lokasi pengabdian (Kelurahan Lakkang, Kota Makassar).

\section{Kesimpulan}

Tingkat partisipasi masyarakat untuk mengikuti kegiatan ini cukup tinggi dibuktikan dengan kehadiran khalayak sasaran mencapai target yang diharapkan (24 orang dari 30 orang yang ditargetkan). Keingintahuan dan minat khalayak sasaran tentang teknologi biofilter dan manfaatnya untuk meningkatkan kualitas air tambak cukup besar dibuktikan dengan keterlibatan secara aktif khalayak sasaran saat penyuluhan. Tersedianya buku saku Panduan Pembuatan Biofilter akan memudahkan petambak dalam membuat biofilter secara mandiri.

\section{Ucapan Terima Kasih}

Penulis mengucapkan terima kasih kepada Lembaga Penelitian dan Pengabdian pada Masyarakat, Universitas Hasanuddin yang telah mendanai kegiatan ini dengan skema Program Kemitraan Masyarakat TA. 2018. Ucapan terima kasih juga dihaturkan kepada petambak udang/ikan, Pak Lurah, Staf administrasi, pegawai Kelurahan Lakkang, masyarakat serta beberapa mahasiswa PS MSP yang telah membantu dan berpartisipasi sehingga kegiatan ini dapat berjalan dengan baik.

\section{Referensi}

Anonim (2018). Lakkang, Tallo, Makassar. Wikipedia.

[https://id.wikipedia.org/wiki/Lakkang,_Tallo,_Makassar, diakses Mei 2018]

Gardy, C.P.L \& Lim, H.C. (1980). Biological Wastewater Treatment: Theory \& Application. New York : Marcell Dekker, Inc.

Hikami, Sumiko., Shinseki rosohou ni yoru mizu shouri gijutsu (1992). Water

Treatment with Submerged Filter), Kougyou Yousui No. 411, 12.

Kudsiah, H., Tresnati, J., \& Ali , S. A. (2018). IbM Kelompok Usaha Bandeng Segar Tanpa Duri di Kabupaten Pangkep Sulawesi Selatan. Panrita Abdi Jurnal, 2(1), 55-63.

Rukminasari, N., Indar, Y.N., Sitepu, F., Parawansa, B.S., Suharto, Irmawati, \& Inaku, D.F. (2016). Pengembangan Bank Sampah Sebagai Upaya Bersih 
Pantai dan Pemberian Nilai Tambah Sampah Daur Ulang di Pantai Losari, Kota Makassar. Jurnal Panrita Abdi, 1(1), 71-75.

Rifa'i, M.A., Kudsiah, H., \& Muzdalifah. (2017). Alih teknologi produksi benih anemon laut secara aseksual. Jurnal Panrita Abdi, 1(1), 33-39.

Rifa'i, M.A., Syahdan, M., Muzdalifah, \& Kudsiah, H. (2018). Pengembangan Usaha Produk Intelektual Kampus: Anemon Laut Ornamen. Jurnal Panrita Abdi, 2(1), 40-47.

Yaqin, K., Fachruddin, L., Yanuarita, D., Suwarni, Umar, M.t., \&.Kudsiah, H. 2017. Transformasi Hama Rumput Laut Menjadi Produk Perikanan. Jurnal Panrita Abdi, 1(2), 76-82.

Penulis:

Nita Rukminasari, Program Studi Manajemen Sumberdaya Perairan, Jurusan Perikanan, Fakultas Ilmu Kelautan dan Perikanan, Universitas Hasanuddin, Makassar. E-mail: nita.r@unhas.ac.id

Nadiarti Nurdin, , Program Studi Manajemen Sumberdaya Perairan, Jurusan Perikanan, Fakultas Ilmu Kelautan dan Perikanan, Universitas Hasanuddin, Makassar E-mail: arti.an.an@gmail.com Khusnul Yaqin , . Program Studi Manajemen Sumberdaya Perairan, Jurusan Perikanan, Fakultas Ilmu Kelautan dan Perikanan, Universitas Hasanuddin, Makassar E-mail: khusnulyaqin@gmail.com Moh. Tauhid Umar, Program Studi Manajemen Sumberdaya Perairan, Jurusan Perikanan, Fakultas Ilmu Kelautan dan Perikanan, Universitas Hasanuddin, Makassar, Email : tauhid.umar72@gmail.com Irmawati, Program Studi Manajemen Sumberdaya Perairan, Jurusan Perikanan, Fakultas Ilmu Kelautan dan Perikanan, Universitas Hasanuddin, Makassar, Email : trif.ahwa@gmail.com.

Dewi Yanuarita, Prodi Manajemen Sumberdaya Perairan, Jurusan Perikanan, Fakultas Ilmu Kelautan dan Perikanan, Universitas Hasanuddin, Makassar. E-mail: dy.satari@yahoo.com

Bagaimana men-sitasi artikel ini:

Rukminasari, N., Nurdin, N., Yaqin, K., Umar, M.T., Irmawati, \& Dewi Yanuarita. (2020). Pengenalan Penggunaan Biofilter sebagai upaya Mengatasi Pencemaran Bahan Organik di Perairan Tambak di Kelurahan Lakkang, Kota Makassar. Jurnal Panrita Abdi, 4(1), 119 - 125. 